\title{
Diagnosing Technique Improvement of Power and Bearing Designs in Vehicle Bodies and Frames
}

\author{
Inar F. Suleimanov*1, Damir A. Kharlyamov ${ }^{2}$, Gennady V. Mavrin ${ }^{3}$, Ilgiz Kh. Khasanov ${ }^{4}$, Vladimir I. \\ Rassokha $^{5}$, Rustem Kh. Khasanov ${ }^{6}$ \\ 1, 2,3 Kazan Federal University, Naberezhnye Chelny Institute, ${ }^{4,5,6}$ Orenburg State University, Faculty of Transport \\ *Email: $\underline{\text { ecolog 777@mail.ru }}$
}

Received: 21st October 2017 Accepted: 16th November 2017, Published: 31st December 2017

\begin{abstract}
This research paper presents theoretical and experimental studies aimed at vehicle operation efficiency increase by improving the diagnosis of power and load-bearing structures of car bodies and frames without labor-intensive assembly and dismantling operations.

Improved and adapted methods of nondestructive control concerning the technical condition of power and load-bearing structures of vehicle bodies and frames allow them to be diagnosed with minimal material and labor costs.

The developed method of identification for power and load-bearing structures of bodies and frames during the retrospection for the participation of vehicles in emergency situations will allow to detect hidden defects, the foci of corrosion damage, to reveal the most loaded elements of bodies and frames for the timely elimination of malfunctions that affect the safety of a car, and also improve the quality of provided services for the maintenance of mobile machines.

The positive effect of the developed measures to improve the methods of power and load-bearing structures diagnosis of vehicle bodies and frames will increase the technical and economic performance of automobile service enterprises, and will expand the scope of their financial and professional activities.

The presented scientific developments, taking into account the conduct of a number of specific experimental observations, can be rationally used to determine the technical state of power and load-bearing structures of other research objects, for example, the ones which are in a static position during their diagnosing.
\end{abstract}

Keywords: Diagnosis, Power and Load-Bearing Structures, Body, Frame, Technical Condition, Vehicle

\section{Introduction}

In recent years, the territory of Russia is characterized by an annual increase of mobile transport system. The major share of growth is accounted for by road transport, where passenger cars make a significant contribution due to the availability of their purchase. With the increase of motorization level explain transport accident rates, which lead to significant social and economic losses of the country. Therefore, the study of problems related to the technical operation of vehicles in the field of system diagnosis responsible for road safety is a priority and a necessary direction for the scientific community.
A body and a frame, being the basic elements of a vehicle, make a significant impact on the overall safety of a car during operation. This is related to the fact that the components and the parts of the steering, braking system and running gear of a car are mounted on the power and load-bearing structural elements of a body and a frame. In this regard, their technical condition has a direct effect on the change of vehicle structural safety indicators.

The control of the technical condition concerning the power and the load-bearing structure of a car body and a frame can be carried out in the following directions: the diagnosis of a system general condition as a power structure, and the control of a body geometric parameters at reference base points.

The power and the load-bearing elements of vehicle bodies are made mainly of rolled sheet steel with the strengthening of their structure by stamping and the provision of a complex box-shaped shape to a section, which provides the greatest strength properties with a smaller mass. During the diagnosing of a vehicle body or a frame general condition they determine the degree of corrosion attack, a crack, the delamination of the protective coating and other defects. At the general estimation of power and bearing design technical condition for bodies and frames the thermal imaging control was applied in this work which allows to reveal the centers of corrosion destructions without the carrying out of labor-consuming assembly dismantling operations that is especially actual for hard-to-reach places of a vehicle [1].

The control of the geometric parameters for the base points of vehicle bodies and frames is based on the determination of control point spatial position correspondence to the manufacturer parameters using modern high-tech equipment, the operation principle of which is based on electronic, optical, ultrasonic, laser or combined distance measurement. When the spatial position of the reference base points of a body or a frame is diagnosed a check is often made for the presence or absence of axle distortion, which can directly affect the handling performance of a car, and hence the safety of traffic [2]. The displacement of the reference body base points during operation or as the result of participation in road accidents with subsequent substandard restoration of a body geometry can be detected from the measurements of installation angles concerning the steered wheels [3-6].

Due to the foregoing, there is a need to implement theoretical and experimental studies focused on the study of preventive, organizational, technical and 
managerial measures to monitor and predict the technical condition of power and load-bearing structures of vehicle bodies and frames.

The proposed development of this scientific work will improve the diagnostic system for the bodies and frames of modern cars of domestic and imported production.

\section{Materials and Methods}

The scientific novelty of this research paper is presented by the results of theoretical and experimental observations concerning the change of the technical state parameters of power and load-bearing structures for vehicle bodies and frames during the operation on the basis of existing methods of nondestructive testing adaptation to the elements of car bodies and frames during their diagnosis [7-11].

The basis for the development of an objective function is the model of the relationship between the diagnostic parameters of a protective coating and reliability

$$
f(L)=\frac{1}{\sqrt{2 \pi}\left|\frac{1}{v} a+a_{1} L+a_{2} L^{2}\right|} \exp \left\{-\frac{\left(L-\bar{L}_{0}\right)^{2}}{2\left(\frac{1}{v} \sqrt{a+a_{1} L+a_{2} L^{2}}\right)^{2}}\right\} .
$$

where $a, a_{1}, a_{2}$ are the coefficients of the approximation function; $\bar{L}_{0}-$ the average arithmetic expression or the mathematical expectation of the mileage of vehicles until the limiting thickness value of the protective coating of a body or a frame is reached, thousand $\mathrm{km}$; L - a car mileage, thousand $\mathrm{km}$.

The basis for the developed technique concerning the predictive assessment of a protective coating technical

$$
\bar{L}_{o c m}=\frac{\bar{d}_{0}-d_{n p e d}-v \bar{L}_{0}-\Delta d}{v},
$$

where $\bar{d}_{0}$ - the mathematical expectation of a protective layer thickness at the initial stage of observation, $\mu \mathrm{m} ; d_{\text {nped }}-$ the extreme value of a protective coating thickness for a body or a frame, $\mu \mathrm{m} ; v$ - the parameter of the formula; $\Delta d-$ the increase of protective coating thickness obtained during the application of anticorrosive materials and in the process of preventive measures during the processing of car bodies and frames. indicators. The mathematical model to be determined is expressed by the moment functions of a random process and is described by the corresponding appressions that can be used to predict the operating time to reach the limit values for the hickness of car body and frame protective coating.

During the technical condition evaluation for power and load-bearing structures of vehicle bodies and frames, it is proposed to use the target function to determine the range of vehicles before reaching the values of protective coating parameter according proposed by Professor Vulman.

The developed analytical dependence helps to determine the permissible and limiting diagnosed values of a protective coating without carrying out long-term operational observations, and also to reveal the required indicators of a protective coating reliability for car bodies and frames according to runup [12].

condition for power and load-bearing structures of car bodies and frames is the establishment of the residual mileage value until the limit values of the protective coating thickness are reached. The general form of the analytical equation is represented by the following mathematical dependence:

\section{Results and Discussion}

The use of existing methods of nondestructive control and their adaptation during the diagnosis of power and load-bearing structures of vehicle bodies and frames depends on the depth of control (table 1), the degree of corrosion destruction, the accuracy of hidden defect detection, the laboriousness of the process concerning the evaluation of research object technical condition, the cost of preventive operations and the complexity of operation technology $[13,14]$.

During the carrying out of practical studies concerning the monitoring of car bodies and frames technical condition, the thermal-graphic method was used, as the most effective one at different stages of diagnosis [15]. 
Helix Vol. 8(1): 2568- 2572

Table 1 - The Short Characteristic of the Existing Control Methods of Technical Condition

\begin{tabular}{|c|c|c|c|}
\hline \multirow{2}{*}{$\begin{array}{l}\text { Control methods of technical } \\
\text { condition }\end{array}$} & \multicolumn{3}{|c|}{ Sensitivity, mm } \\
\hline & width & depth & extent \\
\hline Acoustic ultrasonic & $0,001-0,3$ & $0,1-0,3$ & - \\
\hline Acoustic impedance & $50-100$ & $0,1-1,4$ & 5,0 \\
\hline Capillary luminescent & $0,001-0,002$ & $0,01-0,02$ & $0,1-0,5$ \\
\hline Capillary color & $0,0005-0,001$ & $0,15-0,2$ & $1,0-3,0$ \\
\hline Magnetic powder & 0,001 & $0,01-0,5$ & 0,3 \\
\hline Optical-visual & $0,005-0,01$ & - & 0,1 \\
\hline Radiographic & 0,1 & $\begin{array}{l}1,5-7,0 \% \text { object } \\
\text { thickness }\end{array}$ & - \\
\hline
\end{tabular}

During the process of method establishment concerning the solution of some engineering problems, it becomes necessary to determine the degree of difference in prototypes close in color, for example, when the color of vehicle repair parts is compared with the original factory ones. In this case, it is necessary to find out whether repairs have been carried out on a certain area of a body or not, i.e. whether the power and load-bearing structures were repainted [16].

The performance of this kind of comparison was carried out during the experimental study of the technical condition concerning the protective coating of car bodies and frames on the basis of car service enterprises using a spectrophotometer (Fig. 1).

During the determination of a diffuser for effective paints (metallic and nacre), the value of VCI (visual correlation index) was used. The less the variability of the varnish materials being studied, the lower the VCI value (in the case of the performed studies, the numerical value of this parameter is 0.220 ). The values of tolerances for the quality control of restoration work performance are set by automakers during car body and frame painting.

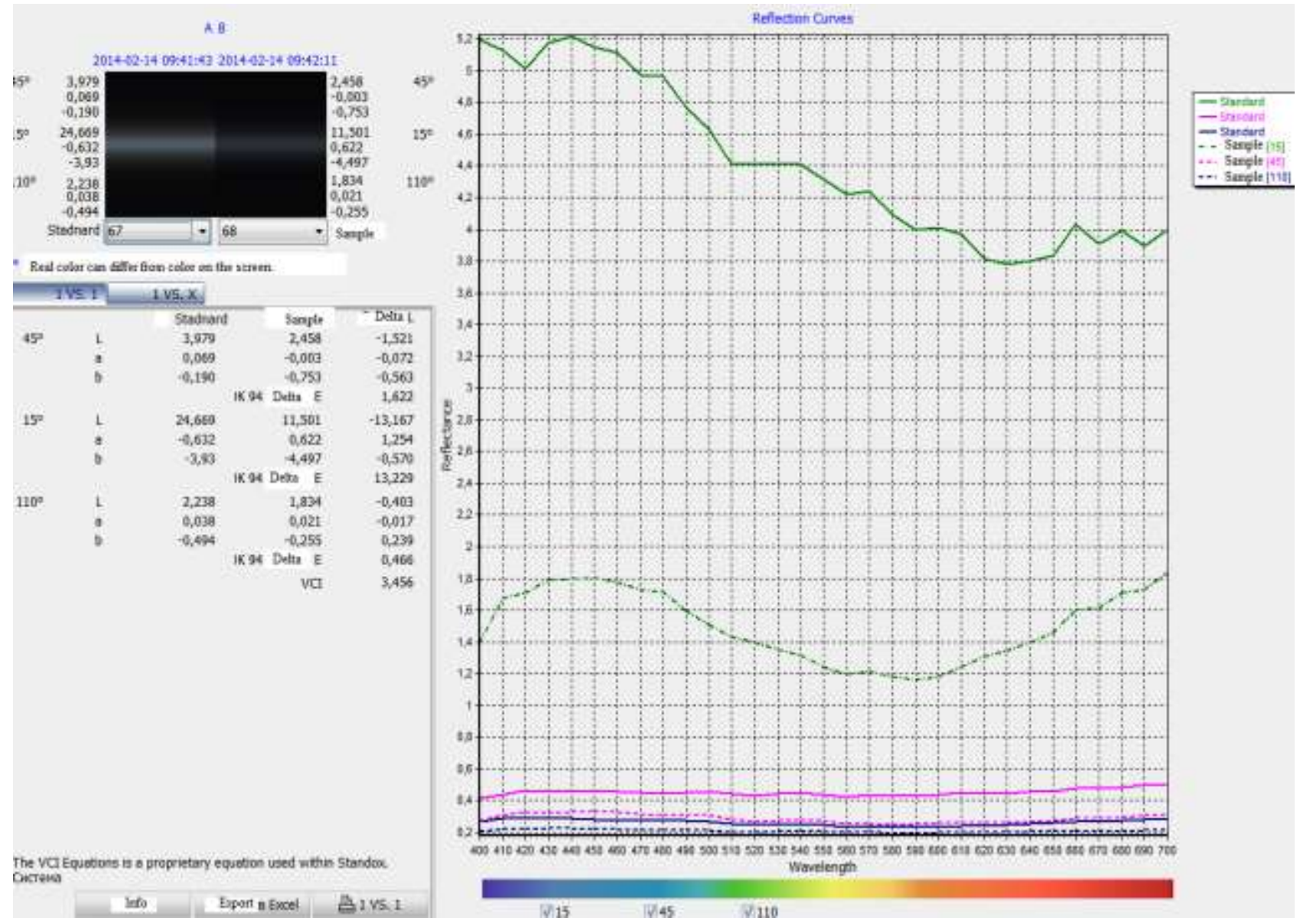

Fig. 1 - Results of control of technical condition of a protective cover of a body with use of the spectrophotometer 


\section{Conclusions}

The proposed method for the diagnosing of power and load-bearing structures of vehicle body and frames allows us to identify the foci of corrosion, hidden defects, the violations of protective and varnish-andpaint materials application technology without long and labor-intensive operations with minimum labor costs.

The developed technique for the determination of power and load-bearing elements of vehicle bodies and frames involvement to damage resulting from road accidents will allow to determine the degree of an emergency object recovery quality and to adjust the amount of natural physical depreciation during the determination of a car residual value.

The scientific observations outlined in this paper will contribute to the improvement of car maintenance quality, and at the carrying out certain measurements during the period of experimental research, it is rational to use the proposed methodology to assess the technical condition of power and load-bearing structures of building and railway facilities during their diagnosing in a static and dynamic position.

\section{Summary}

The carried out researches on the diagnostics of power and bearing structures of bodies and frames of vehicles were performed with the use of modern high-tech equipment on the basis of the dealer centers and carcare centers of Orenburg. The following devices and tools were used during the experimental observations: Qnix 1500 coating thickness gage, Genius spectrophotometer, Olimpus IPLEX LX video camera, Phasec 3d flaw detector and ThermoCAM E 300 thermal imaging camera. The main results of the performed research are published in the collections and the proceedings of scientific papers and conferences of various levels [1-12, 15, 16].

The annual economic benefit from the use of an improved technique for the diagnosing of power and load-bearing structures of vehicle bodies and frames at the station of car maintenance of average power cars will make about 600 thousand rubles on the average.

\section{Acknowledgements}

The work is performed according to the Russian Government Program of Competitive Growth of Kazan Federal University.

\section{References}

1. Khasanov I.Kh., Salikhov E.A., Yapparov F.K. Thermal imaging method to detect the degree of corrosive destruction of a car body. // Progressive technologies in transport systems: the collection of articles of the XIIth International Scientific and Practical Conference. - Orenburg: OSU, 2015. - pp. 363-368.

2. Khasanov I.Kh., Hasanov R.Kh. On the impact of road accidents on the technical condition of cars in the city of Orenburg // Problems of operation, quality and reliability of transport and technological machines: interuniversity collection of scientific papers. Khabarovsk: TOGU, 2005. - pp. 186-191.

3. Bondarenko E.V., Khasanov I.Kh. The analysis of the technical condition of car body influence on the angles of operated controlled wheel mounting // Progressive technologies in transport systems: the collection of reports of the VIIth Russian Scientific and Practical Conference. - Orenburg: GOU OSU, 2005. pp. 327-333.

4. Bondarenko E.V., Apsin V.P., Hasanov I.Kh. To the issue of the technical condition influence concerning the front part of a passenger car body on the corners of operated controlled wheel installation // Bulletin of the Orenburg State University. - 2006. - No. 12 (62). - pp. 438-444.

5. Khasanov I.Kh. The technique of a car body technical condition control on the basis of controlled wheel angle measurement // Bulletin of the Orenburg State University. 2011. - No. 10 (129). - pp. 139-145.

6. Khasanov I.Kh., Hasanov R.Kh. Theoretical justification of the method determining the angles of controlled wheel installation on the changes of the front part of a car body technical condition // Progressive technologies in transport systems: the collection of reports of the VIIIth Russian Scientific and Practical Conference. - Orenburg: GOU OSU, 2005. pp. 316-321.

7. Bondarenko E.V., Golovanov Yu.V., Khasanov I.Kh. Nondestructive testing of paint and varnish coating thickness of a car body // Actual issues of the transport complex innovative development. The materials of the 4th International Scientific and Practical Internet Conference. - Orel: FSBEI HPE "State University - UNPK", 2014. - pp. 24-28.

8. Khasanov I.Kh. Non-destructive control of the technical state of the object under study by the method of capillary defectoscopy // Design and management of highways: reforming of educational programs in Russian Federation. The development and the implementation of master's programs in Russia: the collection of articles of the International Scientific and Practical Conference. - Orenburg: OSU; OOO IPK "University", 2014. - pp. 119-121.

9. Khasanov I.Kh. The improvement of methods for car body diagnosing // Bulletin of the Orenburg State University. - 2015. - No. 4 (179). - pp. 131-135.

10. Khasanov I.Kh., Golovanov Yu.V. Nondestructive control of the technical condition of a car body using a vortex-current method. // Transport and transporttechnological systems: the materials of the International Scientific and Technical Conference. - Tyumen: TyumGNGU, 2014. pp. 259-263. 
11. Khasanov I.Kh. The improvement of the procedure determining the contribution for car insurance taking into account the technical condition of a body // Progressive technologies in transport systems: the collection of articles of the XIth International Scientific and Practical Conference (April 2426, 2013). - Orenburg: State Unitary Enterprise of RB, Kumertau city printing house, 2013. - pp. 542-546.

12. Filatov M.I., Khasanov I.Kh. To the issue of method improvement for the monitoring of passenger car body technical condition // Bulletin of Tula State University. Technical sciences. - 2015. - Issue 6: in 2 parts. Part 1 pp. 172-178.

13. Carsten Keller, Matthias Putz. Forcecontrolled Adjustment of Car Body Fixtures Verification and Performance of the New
Approach // Procedia CIRP. - 2016. V. 44. pp. 359-364.

14. Jaime Molina, J. Ernesto Solanes, Laura Arnal, Josep Tornero. On the detection of defects on specular car body surfaces // Robotics and Computer-Integrated Manufacturing. - 2017. V. 48. - pp. 263-278.

15. Golovanov Yu.V., Khasanov I.Kh. Thermal imaging method to monitor the technical condition of a car body // Bulletin of the Orenburg State University. - 2014. - No. 10 (171). - pp. 54-59.

16. Rassokha V.I., Khasanov I.Kh. Nondestructive method of monitoring the technical state of paint and varnish coating using a spectrophotometer // Bulletin of Tula State University. Technical science. - 2015. Issue 6: in 2 parts. Part 1 - pp. 178-183. 